\title{
PERFORMANCE, COMBUSTION AND EMISSION ANALYSIS OF COMPRESSION IGNITION ENGINE FUELLED WITH BLENDS OF TYRE PYROLYSIS OIL
}

\author{
Sanket S. Mulye ${ }^{1}$ and Milankumar R. Nandgaonkar ${ }^{2}$
}

\begin{abstract}
The depletion of conventional automotive fuels, the increasing number of vehicles and stringent emission norms are the challenges in front of automotive industry. The tyre pyrolysis oil (TPO) is viewed as an attractive alternate fuel for internal combustion engines. Tyre pyrolysis oil is obtained by the pyrolysis of waste tyres. Tyre pyrolysis oil is blended into petroleum diesel in different proportions viz. 10, 20 and 30 percent by volume. The properties of fuel samples are measured by standard methods. The performance, combustion and emission characteristics are studied on a single cylinder, four stroke, water cooled compression ignition engine. Ignition delay for TPO blends is higher than diesel. TPO blends show heat release rate comparable to diesel in premixed phase. TPO blends show high brake specific fuel consumption and low brake thermal efficiency compared to diesel. The TPO diesel blends are found to produce high smoke compared to diesel.
\end{abstract}

Keywords - Tyre pyrolysis oil, Performance, Combustion, Diesel, Smoke

\section{INTRODUCTION}

The conventional automotive fuels are continuously depleting. At the same time, emission norms are becoming stringent. So, researchers all over the world are trying to find renewable and eco friendly fuel. For compression ignition engines, biodiesel, pyrolysis oil and waste oils are considered as alternate fuels. Vegetable oils and animal fats are potential sources of biodiesel. The vegetable oils include jatropha, karanja, mahua, palm, neem, soyabean, sesame [1], [2], [3] etc. Fishes [4] and mutton tallow [5] are major sources of animal fat. The waste oils include waste cooking oil [6], waste lubricating oil [7] etc.

Pyrolysis oil is gaining interest amongst researchers as an alternate fuel for furnaces and internal combustion engines. Wood [8], [9] and waste tyres [10] are pyrolyzed to produce oil. The pyrolysis of tyres can be carried out on bench scale, pilot scale and industrial scale. Rotary kiln pyrolysis, fixed bed pyrolysis, fluidized bed pyrolysis, ablative reactor pyrolysis, flash pyrolysis, catalytic pyrolysis, plasma pyrolysis, molten salt pyrolysis, microwave pyrolysis are different types of bench pyrolysis [11].

Cumali İlkiliç et al. [12] produced TPO from waste tyres by catalytic pyrolysis and studied its performance in diesel engine. The TPO blended into diesel up to $35 \%$ by volume can be used in diesel engine without any engine modifications. Blending of $50 \%$ or more TPO resulted in considerably high $\mathrm{CO}, \mathrm{HC}, \mathrm{SO}_{2}$ and smoke emissions. Murugan et al. [13] used TPO blends into

${ }^{1}$ Department of Mechanical Engineering College of Engineering, Pune, Maharashtra, India

${ }^{2}$ Department of Mechanical Engineering College of Engineering, Pune, Maharashtra, India 
single cylinder diesel engine. They found increase in brake thermal efficiency with increase in TPO concentration. $\mathrm{CO}, \mathrm{HC}$ and $\mathrm{NO}_{\mathrm{x}}$ emissions were increased. Peak pressure and rate of pressure of pressure rise were higher for TPO blends.

Sharma et al. [14] studied performance of DI engine fuelled with blends of jatropha methyl ester (JME) and tyre pyrolysis oil. JMETPO20 given the optimum result. They found significant reduction in $\mathrm{CO}, \mathrm{HC}$ and smoke emissions but $\mathrm{NO}_{\mathrm{x}}$ emissions were increased.

Wongkhorsub et al. [15] compared the performance characteristics of TPO and plastic pyrolysis oil. Tyre pyrolysis offered comparable efficiency to diesel oil in medium to high load. The development of the tyre pyrolysis oil depends on the cost of desulphurization process. Modifications are required in the engine to achieve efficient operation with plastic pyrolysis oil.

\section{EXPERIMENTAL DETAILS}

Tyre pyrolysis oil is blended into petroleum diesel in different percentages viz. 10, 20 and 30\% by volume and referred as TPO10, TPO20 and TPO30 respectively. The properties of the fuel samples i.e. density, kinematic viscosity, calorific value, flash point are measured. The experiments are conducted on a single cylinder, four stroke compression ignition engine whose specifications are given in Table 1. The piezo electric pressure transducer is used to measure cylinder pressure and computerized data acquisition system is used to record the data. The schematic of test rig is shown in Figure 1 and actual view of test rig is shown in Figure 2.

Table-1 Specifications of the test rig

\begin{tabular}{|l|l|}
\hline Make & Kirloskar \\
\hline Model & $240 \mathrm{PE}$ \\
\hline Aspiration & Natural \\
\hline Bore and Stroke & $87.5 \mathrm{~mm}$ X $110 \mathrm{~mm}$ \\
\hline Type of cooling & Water cooled \\
\hline Speed & $1500 \mathrm{rpm}$ \\
\hline Compression ratio & $18: 1$ \\
\hline Power & $3.5 \mathrm{~kW}$ \\
\hline Dynamometer & Eddy current \\
\hline
\end{tabular}

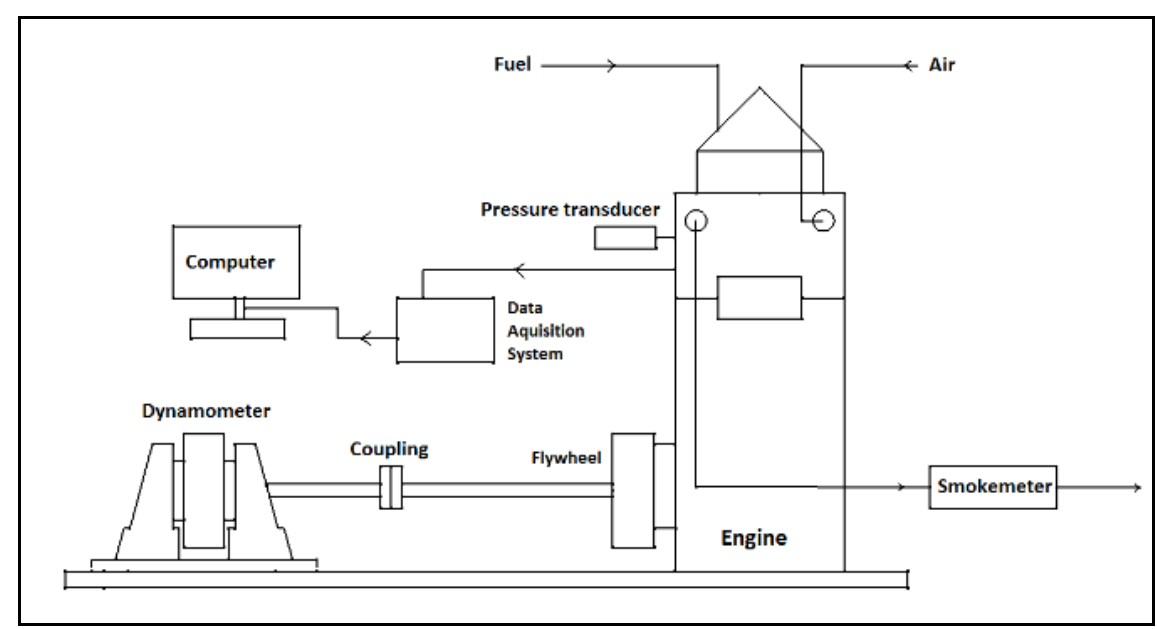

Figure 1. Schematic of Test Rig 


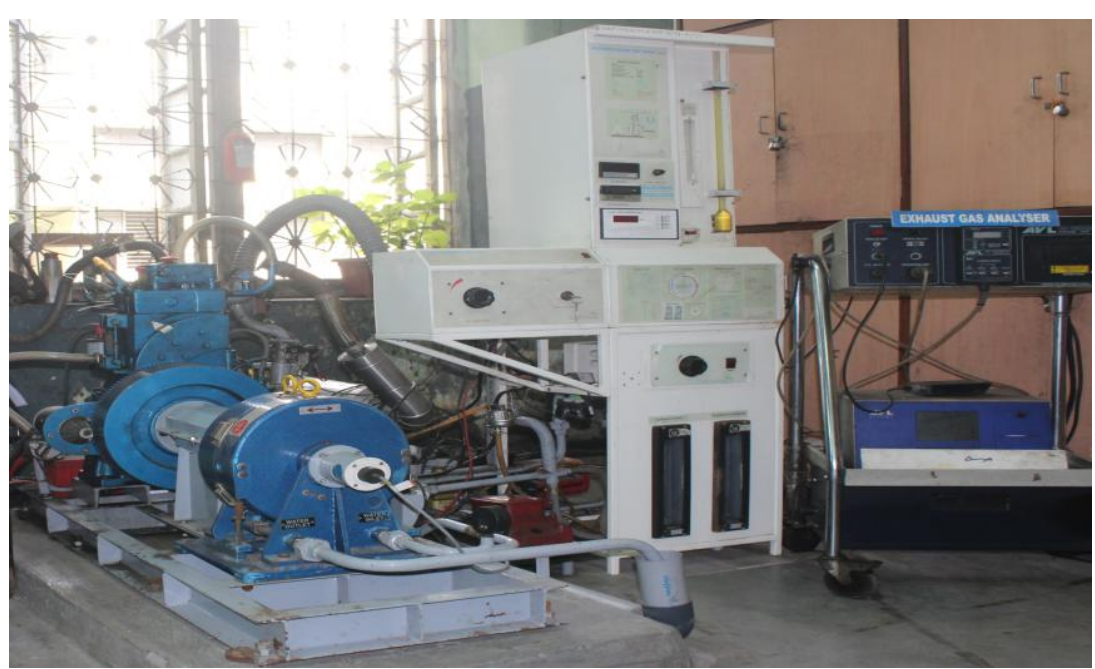

Figure 2. Actual view of Test Rig

\section{RESULTS AND DISCUSSION}

The properties of TPO-diesel blends are compared with properties of diesel. The engine performance is studied under variable load conditions. The engine speed is maintained at 1500 $\mathrm{rpm}$. The obtained data is analyzed and results are presented in this section.

\section{A. Properties of fuel samples}

The properties of petroleum diesel and biodiesel blends are measured and given in Table 2 . The density of all blends is found to be higher than diesel. Higher density of tyre pyrolysis oil is responsible for higher density of blends. The kinematic viscosity of all the blends is higher than diesel. It affects atomization and distribution of injected fuel inside combustion chamber. The flash point decreases with increase in blending percentage. The heating value of the blends is lower than that of diesel. So, as the blending percentage increases, the density and kinematic viscosity of the biodiesel increases and the calorific value, flash point decreases.

Table-2 Properties of fuel samples

\begin{tabular}{|c|c|c|c|c|}
\hline \multirow[b]{2}{*}{ Property } & \multicolumn{4}{|c|}{ Sample } \\
\hline & Diesel & TPO10 & TPO20 & TPO30 \\
\hline Density @ $15^{0} \mathrm{C}\left(\mathrm{kg} / \mathrm{m}^{3}\right)$ & 857.3 & 860.1 & 868.7 & 873.6 \\
\hline Kinematic Viscosity@ 40 $0^{\circ} \mathrm{C}$ ( cSt ) & 2.454 & 3.009 & 3.781 & 4.343 \\
\hline Calorific Value (MJ/Kg) & 42.5 & 41.8 & 40.8 & 39.9 \\
\hline Flash Point $\left({ }^{0} \mathrm{C}\right)$ & 55 & 53 & 40 & 48 \\
\hline
\end{tabular}

\section{B. Combustion characteristics}

The combustion analysis involves the investigation of variation of cylinder pressure and heat release rate with respect to crank angle.

\section{i. Cylinder pressure}

In a compression ignition engine, the peak cylinder pressure depends the ignition delay period and fuel burned in premixed combustion phase. The comparison of the cylinder pressure histories of diesel and TPO blends at full load condition is shown in Figure 3. The cylinder peak pressure is found to be highest for blend TPO 10 where as it is least for diesel. For TPO blends, 
the peak pressure occurs late in the cycle compared to diesel. This is attributed to longer ignition delay for TPO. For efficient operation, the injection timing should be advanced for TPO blends.

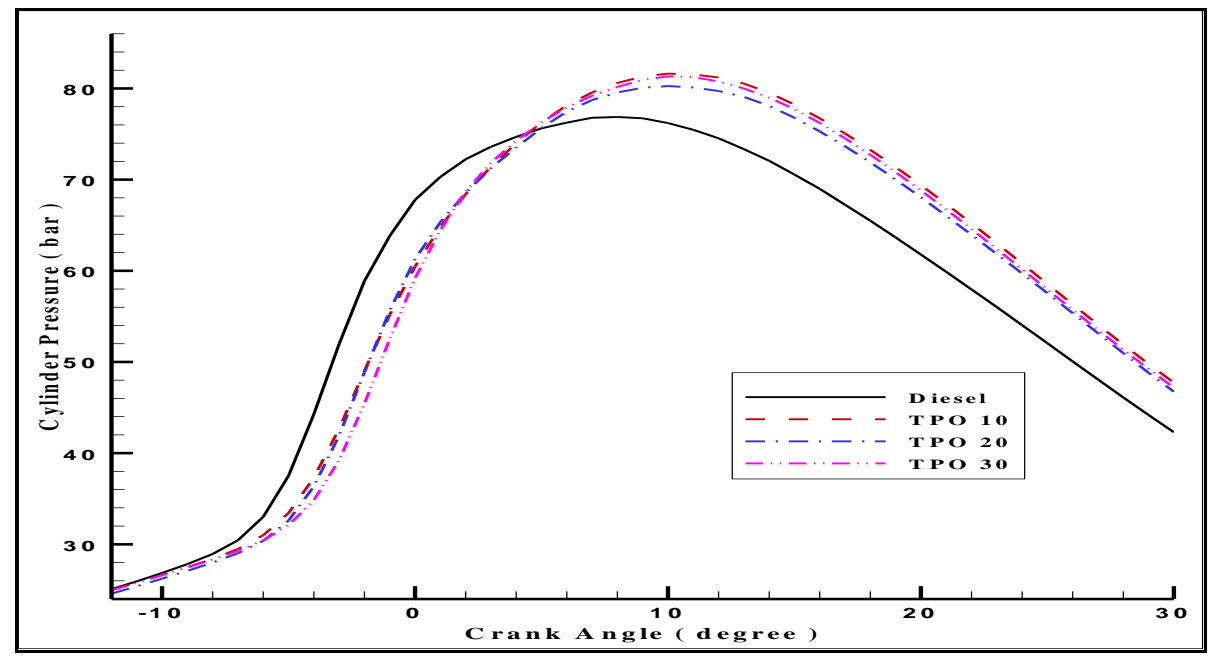

Figure 3. Variation of cylinder pressure with crank angle

\section{ii. $\quad$ Heat release rate}

The heat release in diesel engines occurs in two stages. In first stage called premixed phase, fuel accumulated in the cylinder during ignition delay period burns. In the second stage controlled combustion occurs. The amount of heat release in the premixed combustion of a CI engine depends on the ignition delay, air fuel mixing rate and the heating value of the fuel [16]. Figure 4 shows the heat release pattern of the TPO operation at full load. TPO blends show heat release rate comparable with diesel in premixed phase. In diffusion phase, heat release rate for TPO diesel blends is higher than diesel. This is attributed to more mixture preparation in premixed phase in case of TPO diesel blends.

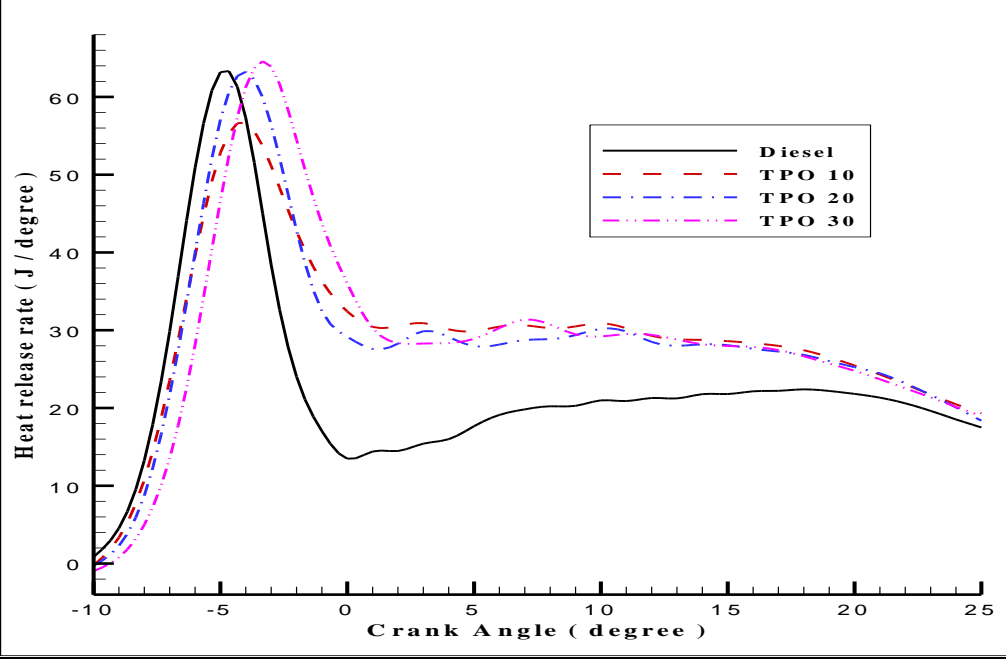

Figure 4. Variation of heat release rate with crank angle 


\section{Performance characteristics}

The engine performance parameters against brake power are plotted to investigate the performance of each fuel sample.

\section{i. $\quad$ Brake specific fuel consumption}

The brake specific fuel consumption (BSFC) is an indicator of the fuel economy for different blending percentages. The variation of BSFC with brake power for fish oil biodiesel blends is shown in Figure 5. It is found that BSFC decreases with brake power. The BSFC for TPO 30 is highest at all the loads. Brake specific fuel consumption increases due to the relative reduction in the calorific value of TPO on a mass basis (MJ / kg), i.e. the loss of calorific value of TPO must be compensated with higher fuel consumption.

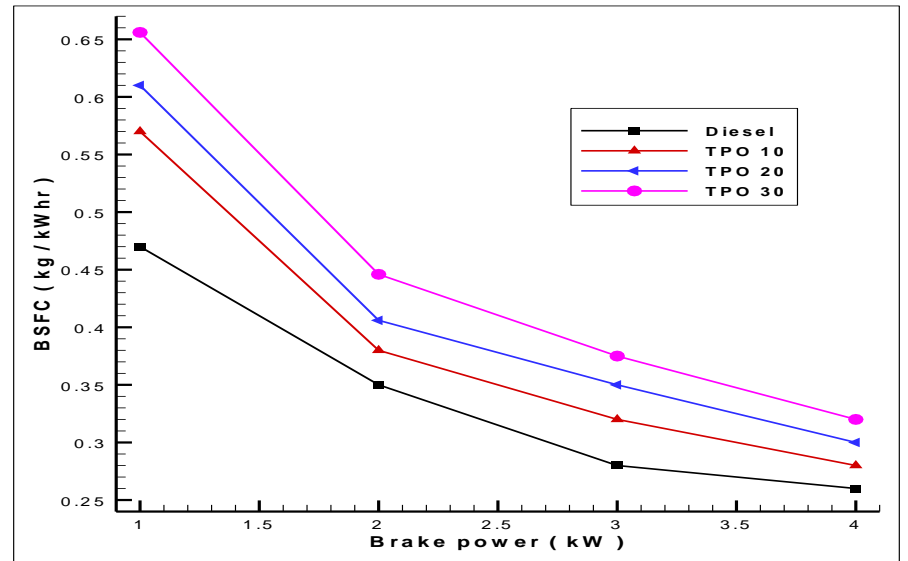

Figure 5. Variation of brake specific fuel consumption with brake power

\section{ii. Brake thermal efficiency}

Brake thermal efficiency gives percentage of energy present in the fuel that is converted into useful work. Variation of brake thermal efficiency with brake power is shown in Figure 6. As load increases, brake thermal efficiency also increases for all the samples. The brake thermal efficiency of diesel at full load is found to be $32.58 \%$. With increase in TPO percentage the overall heating value of the blend decreases. Lower calorific value, higher viscosity and poor mixture preparation are reasons for the lower brake thermal efficiency.

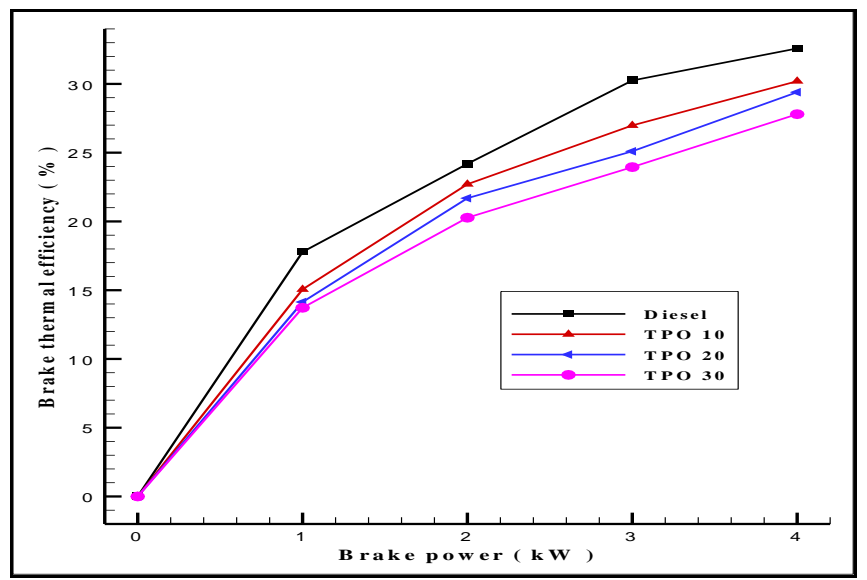

Figure 6. Variation of brake thermal efficiency with brake power 


\section{Emission characteristics}

The exhaust gas analysis is essential in order to test the feasibility of using any fuel by satisfying the emission norms.

\section{i. $\quad$ Smoke opacity}

Smoke is composed of solid soot particles suspended in exhaust gas. The smoke opacity as a function of brake power for all fuels is shown Figure 7. It is observed that smoke opacity is higher with TPO blends at full load. The TPO has high molecular weight and viscosity compared to diesel. They are responsible for poor atomization and ppr mixing with air which results in higher smoke emissions. Also higher aromatic content of TPO contributes to high smoke emission at full load.

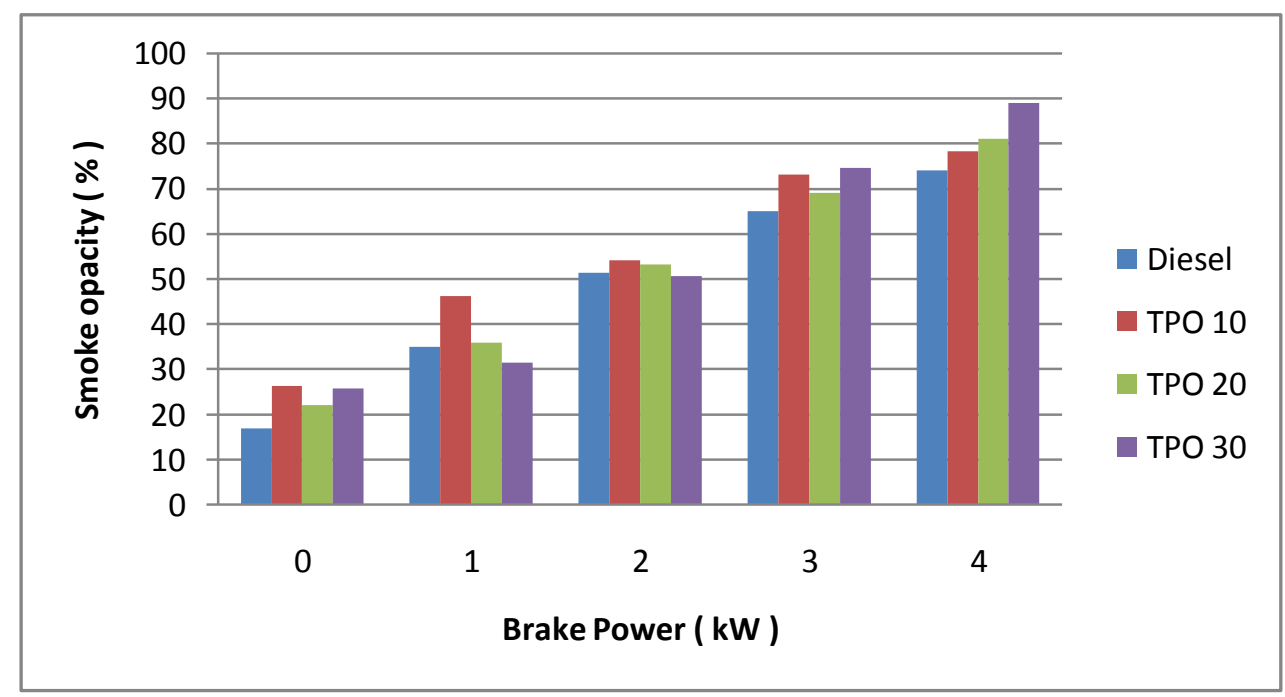

Figure 7. Variation of smoke opacity with brake power

\section{IV.CONCLUSION}

The blends of tyre pyrolysis oil are tested in a CI engine. Engine runs smoothly on the TPO blends. The peak cylinder pressure is found to increase with TPO blends. The injection should be advanced as ignition delay period is higher for TPO blends. As the calorific value of the blended fuels is less than petroleum diesel, brake thermal efficiency decreases with increase in blending percentage. The smoke emissions are found to be higher for TPO blends at full load. Pyrolysis is effective way of disposing waste tyres and process generates gas, oil and char. Thus, tyre pyrolysis oil has potential to be an efficient additive into diesel.

\section{REFERENCES}

[1] Atul Dhar, Roblet Kevin, and Avinash Kumar Agarwal, "Production of biodiesel from high-FFA neem oil and its performance, emission and combustion characterization in a single cylinder DICI engine," Fuel Processing Technology, vol. 97, pp. 118-129, 2012.

[2] R. Banapurmath, P.G. Tewari, and R.S. Hosmath, "Performance and emission characteristics of a DI compression ignition engine operated on Honge, Jatropha and sesame oil methyl esters," Renewable Energy, vol. 33, pp. 1982-1988, 2008.

[3] J Sukumar Puhan, N. Vedaraman, G. Sankaranarayanan, and Boppana V. Bharat Ram, "Performance and emission study of Mahua oil (madhuca indica oil) ethyl ester in a 4-stroke natural aspirated direct injection diesel engine," Renewable Energy, vol. 30, pp. 1269-1278, 2005.

[4] Rasim Behçet, "Performance and emission study of waste anchovy fish biodiesel in a diesel engine," Fuel Processing Technology, vol. 92, pp. 1187-1194, 2011. 
[5] Haq Nawaz Bhatti, Muhammad Asif Hanif, Mohammad Qasim, and Ata-ur-Rehman, "Biodiesel production from waste tallow," Fuel, vol. 87, pp. 2961-2966, 2008.

[6] Anh N. Phan , and Tan M. Phan, "Biodiesel production from waste cooking oils," Vol. 87, pp. 3490-3496, 2008.

[7] Dr. Venkata Ramesh Mamilla, and Dr. Lakshmi Narayana Rao G, "A review: Waste lubricating oil as an alternative fuel blended with diesel," International Journal of Advanced Scientific Research, Vol. 1, no. 1, pp. 01-04, 2016.

[8] Yrj Solantausta, Nils-Olof Nylund, Mfirten Westerholm, Tiina Koljonen, and Anja Oasmaa, "Wood- pyrolysis oil as fuel in a diesel-power plant," Bioresource Technology, Vol. 46, pp. 177-188, 1993.

[9] Dinesh Mohan, Charles U. Pittman Jr., and Philip H. Steele, "Pyrolysis of Wood/Biomass for Bio-oil: A Critical Review," Energy \& Fuels Vol. 20, pp. 848-889, 2006.

[10] P. T. Williams, R. P. Bottrill, and A. M. Cunliffe, "Combustion of tyre pyrolysis oil," Trans IChemE, vol. 76, part B, pp. 291-301, 1998.

[11] N. Antoniou, and A.Zabaniotou, "Features of an efficient and environmentally attractive used tyres pyrolysis with energy and material recovery," Renewable and Sustainable Energy Reviews, vol. 20, pp. 539-558, 2013.

[12] Cumali İlkiliç, and Hüseyin Aydın, "Fuel production from waste vehicle tires by catalytic pyrolysis and its application in a diesel engine," Fuel Processing Technology, vol. 92, pp. 1129-1135, 2011.

[13] S. Murugan, M.C. Ramaswamy, and G. Nagarajan, "The use of tyre pyrolysis oil in diesel engines," Waste Management, vol. 28, pp. 2743-2749, 2008.

[14] Abhishek Sharma, and S. Murugan, "Investigation on the behaviour of a DI diesel engine fueled with Jatropha Methyl Ester (JME) and Tyre Pyrolysis Oil (TPO) blends," Fuel, vol. 108, pp. 699-708, 2013.

[15] C. Wongkhorsub, and N. Chindaprasert, "A Comparison of the Use of Pyrolysis Oils in Diesel Engine” Energy and Power Engineering, vol. 5, pp. 350-355, 2013.

[16] Agrawal AK., "Biofuels (alcohols and biodiesel) applications as fuels for internal combustion engines," Energy Combust Sci, vol. 33, pp. 233-71, 2007. 